\title{
IS SUBSIDIZING ENTRY AN OPTIMAL POLICY?*
}

\author{
by \\ Enrico Santarelli \\ Università di Bologna, Dipartimento di Scienze Economiche
}

and

Marco Vivarelli

Università Cattolica di Piacenza, Dipartimento di Scienze Economiche e Sociali

\begin{abstract}
Public subsidies in support of new firm foundation are among the most frequently used instruments of industrial policy in the Euro zone. This paper analyses their effectiveness and efficiency vis-à-vis some features of the overall process of industry dynamics in Italian manufacturing. To this end, the survival and growth patterns of new small firms are investigated using a unique dataset on electrical and electronic engineering in Italy. As regards survival, our results confirm the findings of other studies, namely that the hazard rates are particularly high in the early stages of firm's life cycle. As far as growth is concerned, the study's main finding is that Gibrat's Law fails to hold in the years immediately following start-up, when smaller firms must 'rush' in order to achieve a size large enough to enhance their likelihood of survival; conversely, in later stages of firm's life cycle the Law cannot be rejected. These results radically question the use of subsidies as an optimal policy for the support of new entries, since the subsidy brings about a major bias in the process of market selection (including substitution and deadweight effects) and hampers the post-entry scale adjustment of newborn firms.
\end{abstract}

May 2000

JEL codes: L11; L50, L60.

Keywords: Entry; young firms; small firms; Gibrat's Law; industrial policy.

Corresponding author: Prof. Enrico Santarelli, Università di Bologna, Dipartimento di Scienze Economiche, Strada Maggiore, 45, I-40125, Bologna;

E-mail: santarel@spbo.unibo.it

\footnotetext{
* We would like to thank Francesca Lotti for careful statistical computation and research assistance. Financial support from MURST is gratefully acknowledged. Although a joint effort, Sections 1 and 4 can be attributed to E. Santarelli, whereas Section 2, 3, and 5 to M. Vivarelli.
} 


\section{Introduction}

From a theoretical point of view, a useful framework for the joint study of the entry and post-entry evolution of newborn firms is the model of noisy selection originally put forward by Boyan Jovanovic (1982) (see also Frank, 1988; Jovanovic, 1994). In this model, newborn firms do not know ex-ante their cost function - that is their relative efficiency - but rather discover it through a process of learning which occurs in the early stages of their life cycle. In other words, entrepreneurs start new firms on the basis of a vague sense of expected profitability, but they only discover their true abilities once their businesses are established. In the periods immediately following foundation, entrepreneurs learn about their abilities and their costs and can thus update their expectations using a Bayesian rule. Those entrepreneurs who discover that their firms are, in fact, efficient will survive and grow, whilst those who discover that their firms are inefficient will tend to exit from the market.

This "try and see" interpretation of the entry and post-entry behavior of new small firms is consistent with strong empirical evidence the following stylized results (see Beesley and Hamilton, 1984; Geroski and Schwalbach, 1991; Geroski, 1995; Audretsch, 1995: Hart and Oulton, 1999):

1) high entry rates are generally associated with high exit rates (turbulence);

2) infant mortality (early exit during the first years after startup) is a frequent phenomenon in most industrial sectors;

3) conditional on survival, small newborn firms exhibit higher growth rates than their larger counterparts (that is, Gibrat's law does not hold for new entrants).

As regards the last point, numerous studies have shown that Gibrat's law does not hold (in the sense that small firms grow faster than larger firms, see - for instance - Mansfield, 1962; Hall, 1987; Evans (1987a and 1987b); Dunne and Hughes (1994); Hart and Oulton (1996) for a comprehensive survey, see Sutton, 1997), and this also applies to samples restricted to newborn firms (see Dunne, Roberts and Samuelson, 1989; Mata, 1994; Audretsch-Santarelli-Vivarelli, 1999a). According to this evidence, surviving new firms which are generally smaller than the minimum efficient scale (MES) in a given sector represent the "efficient group" in Jovanovic's model: they are those firms which discover 
that they have adequate entrepreneurial abilities and thus decide to remain in the market and grow in order to close the gap between their start-up size and the MES.

In this framework, given that subsidies to support new firm creation are a quite common instrument of European industrial policy, the following question arises: are such incentives really useful or do they lead to significant substitution and deadweight effects? In the concluding section of this paper we will try to answer this question. This answer will be based on a representative example of the entry and post-entry evolution of newborn firms in the Italian electric and electronic engineering sector. The purpose is to collect and interpret further empirical evidence in order to characterise the survival and growth patterns of newborn firms and then discuss the possible impact of subsidies on industrial dynamics. In more detail, the paper is organized as follows.

The next section presents the data and methodology. Section 3 discusses patterns of survival: since most of the previous literature has found a positive link between startup size and survival (see Acs and Audretsch, 1989; Audretsch, 1991 and 1995; Wagner 1994; Audretsch and Mahmood, 1995; Baldwin, 1995; Mata, Portugal and Guimaraes, 1995), and since this relationship may be of some help in guiding incentive policy, related estimates are put forward. Section 4 examines patterns of early growth in order to assess the degree to which Gibrat's Law is valid during the first years of firms' life cycles. In microeconomic terms, young firms entering the market at a sub-optimal scale may experience decreasing average costs and enjoy rapid growth, while well-established mature firms can relax along a flattening average cost curve (see Acs and Audretsch, 1990 and Audretsch, 1995). If this is the case, the departure from Gibrat's Law should be more marked in the years immediately after startup. The discussion in Sections 3 and 4 and in the concluding Section 5 will try to put forward some policy suggestions.

\section{Data and methodology}

This section describes the database and discusses the econometric methodology used in the following sections.

The most common obstacle against empirical analysis of the survival and post-entry performance of newborn firms has been the lack of longitudinal data sets tracking the evolution of firms subsequent to their birth. In this paper we use a unique data set obtained from the Italian National Institute for Social Security (INPS). This database 
identifies new firms in electrical and electronic engineering (with at least one paid employee) born in January 1987 and tracks their post-entry employment performance at monthly intervals until January 1993.

Prior to the data processing, the original INPS file was subjected to controls in order to identify entry and failure times correctly and detect inconsistencies in individual tracks due to administrative factors, problems related to file truncation in January 1993, cancellations due to firm transfers, mergers and take-overs. On conclusion of this cleaning process, the dataset identified 129 new firms entering the market in 1987, of which 83 still survived in 1993.

The survival analysis (Section 3) was developed in two stages. Preliminarily, survival and hazard rates were computed. Secondly, the possible positive correlation between startup size and survival (see Section 1) was investigated. This latter analysis was conducted using first a simple logit model (with survival at the end of the period equal to 1 and early failure equal to zero), and then a tobit model which took account of the fact that the data distribution was truncated in January 1993. In this case, the dependent variable was the number of months that each newborn firm had survived during the examined period:

(1) $y_{i}=\alpha+\beta s_{i}+\varepsilon_{i}$

logit model with $y_{i}=1$ in case of survival at the end of the period, $y_{i}=0$ in case of early failure; $\mathrm{s}_{\mathrm{i}}=$ startup size (in terms of employment) $\varepsilon_{\mathrm{i}}=$ random disturbance.

(2) $\mathrm{y}_{\mathrm{i}}=\alpha+\beta \mathrm{s}_{\mathrm{i}}+\varepsilon_{\mathrm{i}}$

tobit model, where $y$ is a random variable obtained from the original one $y^{*}=$ number of months of survival, according to the following truncation rule:

$\mathrm{y}_{\mathrm{i}}=\mathrm{T}$ if $\mathrm{y}^{*} \geq \mathrm{T}$

with T $=72$ months (from January 1987 to January 1993)

$\mathrm{y}_{\mathrm{i}}=\mathrm{y}^{*}$ if $0 \leq \mathrm{y}^{*} \leq \mathrm{T}$ 
The growth analysis (Section 4) starts from observation of average size and growth rates in the relevant period. It will then be developed using the well known logarithmic specification of Gibrat's Law:

(3) $\log S_{i, t}=\beta_{0}+\beta_{1} \log S_{i, t-1}+\varepsilon$

Where $S_{i, t}$ is the size of the ith firm at time $t, S_{i, t-1}$ is the size of the same firm at the previous period and $\varepsilon$ is a random variable distributed independently of $S_{i, t-1}$. Following Chesher (1979, p.404), if both sides of equation (3) are exponentiated, it becomes clear that if $\beta_{1}$ is equal to unity, then growth rate and initial size are independently distributed and Gibrat's Law operates. By contrast, if $\beta_{1}<1$ smaller firms grow at a systematically higher rate than do their larger counterparts, while the opposite is the case if $\beta_{1}>1$.

If - as in the majority of previous studies (see Section 1) - growth and exit are not treated as homogeneous phenomena (that is, assuming the disputable hypothesis that exit is equal to a minus one rate of growth), empirical estimates need deal only with surviving firms. However, the sample selection problem arises here. Since growth can only be measured for firms which have survived over the entire period examined, and since slow growing firms are more likely to exit, small fast growing firms may be overrepresented in the surviving sample and this may bias the results of the empirical research. The appropriate econometric method to deal with this problem is the two-step procedure suggested by Heckman (1979) (see also Amemiya, 1984). This specification introduces into the main equation an additional explanatory variable (the inverse Mill's ratio) obtained by a probit model (selection equation) which estimates the relationship between firm's survival and firm's size at the beginning of the period:

$$
\begin{aligned}
& P\left(f_{i}=1\right)=F\left(\delta+\gamma \log S_{i, t-1}+\varphi \log S_{i, t-1}^{2}+\mu\right) \\
& \text { with: } f_{i}=1 \text { survivor at time } t ; \quad f_{i}=0 \text { exit at time } t ; \mu=\text { disturbance }
\end{aligned}
$$

Since the relationship between size and survival can theoretically assume a non-linear feature, a squared term has been introduced in the selection equation. While equation (3) in isolation was preliminary estimated by means of OLS, the sample selection model 
including equation (4) was estimated using a maximum likelihood two stages method. Tests for heteroskedasticity were carried out using the OLS estimations of (3) and White's (1980) correction was introduced when necessary, both in the OLS and in the sample selection model (SSM) estimations.

\section{Survival analysis}

Table 1 gives the yearly patterns of survival for the 129 newborn firms. It will be noted that there is a dramatically high incidence of early failure, especially in the very first years of firms' life cycles. Consistently with other studies (see Boeri and Cramer, 1992; Mata and Portugal, 1994; Mata-Portugal-Guimaraes, 1995; Audretsch and Mahmood, 1995; Audretsch-Santarelli-Vivarelli, 1999b), the hazard rate reaches a peak in the second year of activity and then displays a decreasing - although not monotonic - trend.

Table 1: Survival and hazard rates

\begin{tabular}{c|c|c|c|c}
\hline Year & Survived Firms & Survival Rate & Exited Firms & Hazard Rate \\
\hline $\mathbf{1 9 8 7}$ & 129 & & & \\
\hline $\mathbf{1 9 8 8}$ & 123 & $95,35 \%$ & 6 & $4,65 \%$ \\
\hline $\mathbf{1 9 8 9}$ & 104 & $80,62 \%$ & 19 & $15,45 \%$ \\
\hline $\mathbf{1 9 9 0}$ & 101 & $78,29 \%$ & 3 & $2,88 \%$ \\
\hline $\mathbf{1 9 9 1}$ & 94 & $72,87 \%$ & 7 & $6,93 \%$ \\
\hline $\mathbf{1 9 9 2}$ & 86 & $66,67 \%$ & 8 & $8,51 \%$ \\
\hline $\mathbf{1 9 9 3}$ & 83 & $64,34 \%$ & 3 & $3,49 \%$ \\
\hline
\end{tabular}

note: hazard rates have been computed as the ratio of firms exiting the market in year t to the number of firms survived at the end of year $\mathrm{t}-1$.

This preliminary evidence is consistent with Jovanovic's (1982) model: in the early stages of a firm's life cycle, less efficient entrepreneurs realize that their cost functions are higher than expected and decide to exit (in this particular population more than one third of new entrants leave the market within the sixth year of activity).

Given the theoretical framework briefly summarized in Section 1 and the evidence reported in table 1, one may question the role of subsidies to support the startup of new firms. Indeed, these incentives allow the cost functions to move downwards and thus heavily interfere with the market selection of less efficient entrepreneurs; accordingly, the availability of subsidies has a twofold effect: entry rates increase, and so too do 
survival rates in the first years following start-up. If entry can be seen as a "try and see" process, the subsidy causes severe distortions: on the one hand, increased entry rates may also involve an increased number of early failure once the effect of the subsidy is over (turbulence); on the other hand, the process of market selection is biased and delayed, so that less efficient entrepreneurs are allowed to remain in the market until the subsidy ceases to be in operation.

In other words, if the selection process reported in table 1 is the outcome of a Bayesian process of learning, a subsidy may be both useless (the more efficient entrepreneur does not need it, while the less efficient one leaves the market once the subsidy ceases to be in operation) and harmful (less efficient entrepreneurs are given an artificial seedbed, while market competition would have induced them to leave the market). If the former situation is prevalent, the industrial policy supporting entry is affected by a "deadweight" component; if the latter is prevalent a "substitution" effect arises.

In both cases overall entry subsidies bias market competition; in terms of industrial policy two possible alternatives are available. Either interventions are shifted from subsidizing entry to a post-entry policy or incentives to entry are made conditional on some measures of efficiency. In the final section of this paper, the advantages of a postentry policy will be discussed; here some evidence is presented which argues against the use of start-up size as an ex-ante measure of efficiency.

As discussed in Section 1, startup size is often used as an indicator of better chances of survival: indeed, a larger startup size can be seen as either a measure of substantial sunk costs (implying higher barriers to exit) or as a strong commitment by the entrant (and thus as a signal of a higher efficiency). If such is the case - in order not to give the subsidy to the less efficient entrepreneurs (substitution effect) - the policy intervention can make the incentive conditional on the size of the recipient. It is important to note that this policy option reduces the risk of wasting public money, but it raises the opposite problem of a possible "deadweight" effect: the recipient is likely to turn out to be efficient and so does not need the subsidy.

In table 2, the relationship between startup size and survival is tested using our sample and according to the methodology discussed in the previous section. It will be seen that there is no significant evidence that the likelihood of survival tends to be higher for firms whose startup size is larger. 
Table 2: The relationship between start-up size and survival

\begin{tabular}{c|c|c|c}
\hline Model & Constant & Start-up Size & Observations \\
\hline logit & 0.567 & 0.002 & 129 \\
& $(2.93)$ & $(0.37)$ & \\
\hline tobit & 89.48 & 0.043 & 129 \\
& $(11.41)$ & $(0.26)$ & \\
\hline
\end{tabular}

note: t-statistics in parentheses

Thus, at least in Italian electrical and electronic engineering, startup size cannot be considered a good proxy for post-entry efficiency and the likelihood of survival. This evidence, together with the possible occurrence of deadweight effects, suggests that entry subsidies are hardly not associated with a high degree of market distortion.

\section{Growth analysis}

Not only does the entry subsidy imply a strong bias against natural market selection, but it may also interfere with the growth patterns of newborn firms (both efficient and inefficient). The general hypothesis tested in this section is that post-entry growth patterns may be driven by the same learning process as described in Section 1. In particular, given the minimum efficient scale of the sector, it may be that efficient smaller firms need to grow faster in order to survive, compared to their larger counterparts.

In this context, the empirical test of equation (3) may provide an answer to the following two questions:

a) Is the overall inverse relationship between size and growth - found by most previous studies on Gibrat's Law- confirmed during the infancy of newborn firms (that is, within a sub-population of new entrants)?

b) Is there convergence on a Gibrat-like pattern of growth with the passage of time?

If the two above hypotheses were jointly supported by the data, Gibrat's Law would exhibit a behavior dependent on firm's life cycle: the Law would fail to hold during the first years after entry and would become acceptable once a given threshold in terms of size and age had been reached. If such were the case, the evidence would support the idea that in the first years after entry the learning process generates two important adjustments: on the one hand, the less efficient firms exit from the market (see previous 
section); on the other, the surviving efficient firms adjust their size in order to cope with market competition.

The descriptive statistics in table 3 provide an overview of new firms' patterns of growth in Italian electrical and electronic engineering.

Table 3: Average Size (S.), Growth Rate (G.) and standard deviations (S.D.): firms still alive at the end of each period

\begin{tabular}{c|c|c|c|c|c|c|c|c|c|c|c|c|c}
\hline S. 87 & S.D.87 & S. 88 & S.D.88 & S. 89 & S.D.89 & S. 90 & S.D.90 & S. 91 & S.D.91 & S. 92 & S.D.92 & S. 93 & S.D.93 \\
\hline 12.40 & 38.92 & 15.41 & 46.27 & 20.01 & 59.57 & 20.89 & 63.46 & 22.23 & 68.80 & 23.90 & 69.22 & 23.42 & 65.05 \\
\hline & & G. 88 & S.D.88 & G. 89 & S.D.89 & G. 90 & S.D.90 & G. 91 & S.D.91 & G. 92 & S.D.92 & G. 93 & S.D.93 \\
\hline & & 0.97 & 1.91 & 0.28 & 0.59 & 0.11 & 0.36 & 0.08 & 0.36 & 0.03 & 0.32 & -0.02 & 0.25 \\
\hline
\end{tabular}

The upper panel of the table reports the average size at the beginning of each of the six years examined and the corresponding standard deviations, whereas the lower panel documents average growth rates. It will be seen that average growth is particularly marked in the first year after entry $(0.97)$, followed by a drop in the second year $(0.28)$ and a further monotonic decline in the years thereafter. This preliminary result suggests the presence of a discontinuity in new firms' patterns of growth during the early stages of their life cycles (see below).

Table 4 reports the OLS and SSM results from the estimations of equation (3). The results from the corresponding selection equations are not given but are available from the authors upon request. The first two columns in the table report the results from the estimations carried out for the entire six-year period (88-93), along with the usual statistical diagnoses (including the correlation between the selection and growth equation, $\rho$ ) and a specific $t$ test for the validity of Gibrat's Law ( $\beta_{1}=1$; question (a) above). The final rows report White's test for heteroskedasticity (when significant a consistent covariance matrix has been used) and sample sizes with and without exits. In the following columns the same estimations are repeated for each year, in order to characterize the possible convergence path with the passing of time (question (b) above). Thus, 14 estimates are presented in table 4 .

We first consider the results for the six-year period (88-93). In both the OLS and the SSM models, estimates of $\beta_{1}$ are significantly less than one: the coefficient is equal to 0.61 in both the estimates, is significant at the $99 \%$ level of confidence and the $t$ test rejects the hypothesis of $\beta_{1}=1$ at the $99 \%$ level of confidence. This result confirms that, 
in general, smaller firms grow faster than their larger counterparts and this is consistent with the previous empirical literature on Gibrat's Law.

More interesting results are yielded by the separate estimations carried out for each year. Indeed, Gibrat's Law fails to hold in the two years immediately following start-up, whereas it cannot be rejected when firms approach maturity. In more detail, in the first and second year following start-up the SSM estimate yields a $\beta_{1}$ significantly less than one, with a value of 0.73 in 1988 and 0.89 in 1989; in the following years, both the SSM estimates (when available) and the OLS estimates increase almost monotonically towards 1 (and the $t$ test does not reject the Law).

Thus, one finds that smaller newborn firms rush to achieve an acceptable size immediately after their start-ups, but once they reach (in subsequent years) a size large enough to enhance their likelihood of survival, their pattern of behavior matches that of larger newborn firms. Thus, Gibrat's Law of proportionate effect exhibits a behavior which depends on the life cycle of the firm.

Both the questions raised above can be answered in the affirmative: not only is the overall inverse relationship between size and growth confirmed during the infancy of newborn firms, but there is a detectable convergence towards a Gibrat-like pattern of growth with the passage of time. This means that - within the sub-population of new entrants - smaller firms, which entered at a sub-optimal scale, must initially rush in order to reach a size comparable to that of larger entrants, while subsequently they converge towards random growth rates (Gibrat-like).

These results indicate that the years immediately after the foundation of a new firm can be interpreted as a process of learning (see Section 1), selection (see Section 3) and scale adjustment (see this section). 
Table 4: OLS and Sample Selection Model (SSM) estimates of Gibrat's Law (equation (3))

\begin{tabular}{|c|c|c|c|c|c|c|c|c|c|c|c|c|c|c|}
\hline & $\begin{array}{c}\text { OLS 88- } \\
93\end{array}$ & $\begin{array}{c}\text { SSM 88- } \\
93\end{array}$ & OLS 88 & SSM 88 & OLS 89 & SSM 89 & OLS 90 & SSM 90 & OLS 91 & SSM 91 & OLS 92 & SSM 92 & OLS 93 & SSM 93 \\
\hline$\beta_{0}$ & $1.36^{* * *}$ & $1.30 *$ & $0.80 * * *$ & $0.72 * * *$ & $0.40 * * *$ & $0.35^{*}$ & 0.11 & (a) & 0.06 & $0.19 *$ & -0.10 & -0.10 & -0.10 & (a) \\
\hline$\beta_{1}$ & $0.61 * * *$ & $0.61 * * *$ & $0.71 * * *$ & $0.73 * * *$ & $0.88 * * *$ & $0.89 * * *$ & $0.97 * * *$ & & $0.98 * * *$ & $0.94 * * *$ & $1.04 * * *$ & $1.04 * * *$ & $1.02 * * *$ & \\
\hline$\rho$ & - & 0.12 & - & $1.00 * * *$ & - & 0.31 & - & & - & $-0.93 * * * *$ & - & -0.01 & - & \\
\hline $\mathrm{t}\left(\beta_{1}=1\right)$ & $4.11 * * *$ & $4.63 * * *$ & $3.63 * * *$ & $5.06 * * *$ & $3.00 * * *$ & $1.92 *$ & 1.00 & & 0.50 & 1.29 & 1.00 & 0.44 & 0.67 & \\
\hline $\mathrm{F}$ & $58.80 * * *$ & $29.04 * * *$ & $\begin{array}{c}201.51 * * \\
*\end{array}$ & $\begin{array}{c}108.55^{* *} \\
*\end{array}$ & $\begin{array}{c}759.69 * * \\
*\end{array}$ & $\begin{array}{c}443.18 * * \\
*\end{array}$ & $\begin{array}{c}768.45^{* *} \\
*\end{array}$ & & $\begin{array}{c}577.28 * * \\
*\end{array}$ & $\begin{array}{c}286.31 * * \\
*\end{array}$ & $\begin{array}{c}763.13 * * \\
*\end{array}$ & $\begin{array}{c}377.07 * * \\
*\end{array}$ & $\begin{array}{c}1157.33 * \\
* *\end{array}$ & \\
\hline $\mathrm{R}^{2}$ adj. & 0.41 & - & 0.62 & - & 0.88 & - & 0.89 & - & 0.86 & - & 0.90 & - & 0.93 & \\
\hline LRI & - & 0.19 & - & 0.34 & - & 0.80 & - & & - & 0.70 & - & 0.78 & - & \\
\hline White $^{\S}$ & $2.67 *$ & - & $7.41 * * *$ & - & $7.11 * * *$ & - & 1.00 & - & 0.32 & - & 1.48 & - & $5.87 * * *$ & \\
\hline N. tot & \multicolumn{2}{|c|}{129} & \multicolumn{2}{|c|}{129} & \multicolumn{2}{|c|}{123} & \multicolumn{2}{|c|}{104} & \multicolumn{2}{|c|}{101} & \multicolumn{2}{|c|}{94} & \multicolumn{2}{|c|}{86} \\
\hline $\begin{array}{l}\text { N. } \\
\text { surv. }\end{array}$ & \multicolumn{2}{|c|}{83} & \multicolumn{2}{|c|}{123} & \multicolumn{2}{|c|}{104} & \multicolumn{2}{|c|}{101} & \multicolumn{2}{|c|}{94} & \multicolumn{2}{|c|}{86} & \multicolumn{2}{|c|}{83} \\
\hline
\end{tabular}

notes: $* * *=$ significant at $99 \%$ level of confidence $* *=$ significant at $95 \%$ level of confidence; $*=$ significant at $90 \%$ level of confidence

$\S$, F- statistic; null hypothesis: homoskedasticity; in case of heteroskedasticity (at least at $90 \%$ level of confidence) a consistent covariance matrix was used (White's correction).

(a) the algorithm did not reach convergence. 


\section{Conclusions and policy implications}

The example of Italian electrical and electronic engineering shows that the early stages of a firm's life cycle are quite important in terms of market competition. Bayesian learning processes and market selection jointly drive less efficient firms out of the market, while the surviving ones adjust their scale towards the average and then behave following a Gibrat-like pattern of growth.

In this context, subsidizing entry may be risky for at least three reasons:

1) less efficient firms are artificially supported and do not leave the market (substitution effect against more efficient potential entrants);

2) in seeking to avoid (1) - for instance by giving subsidies conditional on an aboveaverage startup size - public subsidies may generate a deadweight effect: the beneficiaries would have survived and grown even without the subsidy (in addition, table 2 casts some doubt on the alleged link between startup size and efficiency);

3) an entry subsidy may also bias the adjustment process that takes place in the very first years after entry: in that period, efficient firms which have entered the market at a very low, sub-optimal scale survive through accelerated growth (Gibrat's law does not hold), while in subsequent years the entire cohort of newborn firms assumes a Gibrat-like behavior: In this connection, the presence of a subsidy may confuse the entrepreneur's interpretation of the signals emitted by the market and deter him/her from entering the optimal growth pattern.

The latter point suggests that a shift from overall entry subsidies towards a policy more focused on post-entry might be beneficial in terms of welfare; indeed, a subsidy conditional on survival up to - say - the fourth year of activity, would allow teh market to select out the less efficient entrants and firms to adjust their scale on the basis of previous learning. Thus, post-entry subsidies would avert the substitution effect and would not bias the process of scale adjustment; of course, the deadweight component would remain and should be compared against the possible welfare gains associated with the post-entry subsidy. 


\section{References}

Acs, Zoltan J. and David B. Audretsch, 1989, "Births and Firm Size", Southern Economic Journal, 56, 467-475.

Acs, Zoltan J. and David B. Audretsch, 1990, Innovation and Small Firms, Cambridge (Mass.), MIT Press.

Amemiya, Takeshi, 1984, "Tobit Models: A Survey", Journal of Econometrics, 24(1/2), pp. 3-61.

Audretsch David B., 1991, "New-Firm Survival and the Technological Regime", Review of Economics and Statistics, 73, pp. 441-450.

Audretsch, David B., 1995, Innovation and Industry Evolution, Cambridge (Mass.), MIT Press.

Audretsch, David B. and Talat Mahmood, 1995, "New Firm Survival: New Results

Using a Hazard Function", Review of Economics and Statistics, 77, pp. 97-103.

Audretsch, David B., Santarelli, Enrico and Marco Vivarelli, 1999a, "Start Up Size

and Industrial Dynamics: Some Evidence from Italian Manufacturing", International Journal of Industrial Organization, 17, pp. 965-983.

Audretsch, David B., Santarelli, Enrico and Marco Vivarelli, 1999b, "Does Startup Size Influence the Likelihood of Survival?", in Audretsch, D - Thurik, R. (eds.), Innovation, Industry Evolution and Employment, Cambridge, Cambridge University Press, pp. 280-296.

Baldwin, John R., 1995, The Dynamics of Industrial Competition: A North American Perspective, Cambridge, Cambridge University Press.

Beesley, M.E. and R.T. Hamilton, 1984, "Small Firms' Seedbed Role and the Concept of Turbulence", Journal of Industrial Economics, 33(2), pp. 217-231.

Boeri, Tito and Ulrich Cramer, 1992, "Employment Growth, Incumbents and Entrants: Evidence from Germany”, International Journal of Industrial Organization, 10, pp. 545-566.

Chesher, Andrew, 1979, "Testing the Law of Proportionate Effect", Journal of Industrial Economics, 27(4), pp. 403-411.

Dunne, Paul and Alan Hughes, 1994, "Age, Size, Growth and Survival: UK Companies in the 1980s", Journal of Industrial Economics, 42(2), pp. 115-140.

Dunne, Timothy, Mark J. Roberts and Larry Samuelson, 1989, "The Growth and Failure of US Manufacturing Plants”, Quarterly Journal of Economics, 104(4), pp. 671698.

Evans, David S., 1987a, "The Relationship Between Firm Growth, Size, and Age: Estimates for 100 Manufacturing Industries”, Journal of Industrial Economics, 35(4), pp. 567-581.

Evans, David S., 1987b, “Tests of Alternative Theories of Firm Growth", Journal of Political Economy, 95(4), pp. 657-674.

Frank, Murray Z., 1988, “An Intertemporal Model of Industrial Exit”, Quarterly Journal of Economics, 103, pp. 333-344.

Geroski, Paul A., 1995, "What do we Know about Entry?", International Journal of Industrial Organization, 13(4), pp. 421-440.

Geroski, Paul A. and Schwalbach, Joachim (eds.), 1991, Entry and Market Contestability: An International Comparison, Oxford, Basil Blackwell.

Hall, Bronwyn, 1987, "The Relationship Between Firm Size and Firm Growth in the US Manufacturing Sector", Journal of Industrial Economics, 35(4), pp. 583-606.

Hart, Peter E. and Nicholas Oulton, 1996, "Growth and Size of Firms", Economic Journal, 106(3), pp. 1242-1252. 
Hart, Peter E. and Nicholas Oulton, 1999, "Gibrat, Galton and Job generation", International Journal of the Economics of Business, 6(2), pp. 149-164.

Heckman, James J., 1979, "Sample Selection Bias as a Specification Error", Econometrica, 47(2), pp. 153-161.

Jovanovic, Boyan, 1982, "Selection and Evolution of Industry", Econometrica, 50, pp. 649-670.

Jovanovic, Boyan, 1994, "Firm formation with Heterogeneous Management and Labor Skills", Small Business Economics, 6, pp. 185-191.

Mansfield, Edwin, 1962, "Entry, Gibrat's Law, Innovation, and the Growth of Firms", American Economic Review, 52(5), pp. 1023-1051.

Mata, José, 1994, "Firm Growth During Infancy", Small Business Economics, 6(1), pp. 27-40.

Mata, Jose' and Pedro Portugal, 1994, "Life Duration of New Firms", Journal of Industrial Economics, 42(3), pp. 227-246.

Mata, Jose', Pedro Portugal and Paulo Guimaraes, 1995, "The Survival of New Plants: Start-up Conditions and Post-entry Evolution", International Journal of Industrial Organization, 13, 459-482.

Sutton, John, 1997, "Gibrat's Legacy", Journal of Economic Literature, 35(1), pp. 40-59.

Wagner, Joachim, 1994, "The Post-entry Performance of New Small Firms in German Manufacturing Industries", Journal of Industrial Economics, 42(2), pp. 141154.

White, Halbert, 1980, "A Heteroskedasticity-Consistent Covariance Matrix Estimator and a Direct Test for Heteroskedasticity”, Econometrica, 48(4), pp. 817-838. 